\title{
Determination of the Theoretical and Actual Working Volume of a Hydraulic Motor
}

\author{
Pawel Sliwinski $\mathbb{D}$ \\ Faculty of Mechanical Engineering, Gdansk University of Technology, 80-233 Gdansk, Poland; \\ pawel.sliwinski@pg.edu.pl
}

Received: 9 October 2020; Accepted: 11 November 2020; Published: 13 November 2020

\begin{abstract}
A new methodology of determination of the theoretical and actual working volume of a hydraulic motor based on the characteristics of the delivered flow rate into hydraulic motor vs. the rotational speed at a constant pressure drop in the working chambers is described in this paper. A new method of describing the delivered flow rate into a motor per one shaft revolution as a nonlinear function of the pressure drop in the motor working chamber is proposed. The influence of the flowmeter location in the measurement system on the result of the theoretical and actual working volume calculation is described. It is shown that, in order to assess the energy losses (volumetric and mechanical) in the motor, the actual working volume must be a polynomial function (third degree) of its pressure drop in the working chambers. The result of the experimental tests of the satellite hydraulic motor confirmed the validity of the proposed method. The result of the calculation of the theoretical working volume of the motor according to the proposed method was compared with the results of calculations according to known methods.
\end{abstract}

Keywords: theoretical working volume; actual working volume; hydraulic motor; volumetric efficiency; mechanical efficiency

\section{Introduction}

A hydraulic motor is a principal component of a hydraulic system, and the steady-state behavior of this motor plays an important role in the overall performance of the hydraulic system. The knowledge of the basic characteristics of the motor, such as its volumetric losses efficiency and mechanical-pressure efficiency, is essential for both users and designers of a hydraulic system. So far, the so-called theoretical working volume $q_{t}$ has been used to assess the losses in the motor and its partial efficiency, that is:

(a) the volumetric efficiency:

$$
\eta_{v}=\frac{q_{t} \cdot n}{q_{t} \cdot n+Q_{v}}
$$

(b) the hydraulic-mechanical efficiency:

$$
\eta_{h m}=2 \pi \cdot \frac{M}{q_{t} \cdot \Delta p}
$$

where:

- $Q_{\mathrm{v}}$-the volumetric losses in the motor;

- $n$-rotational speed of the motor shaft;

- $M$-load of the motor; 
- $\Delta p$-pressure drop measured in the motor ports.

The literature describing the method of determining the theoretical working volume of a displacement machine is relatively scarce. The first method of determining the theoretical working volume was described by Wilson (1950), Schlosser and Hilbrands in 1963 [1-4]. This method was improved and described by Toet in 1970 [5]. The same method, but supplemented, was described by Toet once again in 2019 [6]. Nevertheless, Balawender's method from 1974 is commonly used in research and development centers. This method is described in detail in [7,8]. Nevertheless, it is Toet's method from 1970 that is referred to or used in the other available literature [9-12]. Toet's and Balawender's methods are described in the next section.

The simplest of all the known methods of determining the theoretical working volume is presented in the ISO standard [13] (also described in the next section).

Another original method is proposed by Kim in [14]. Kim has attempted to calculate the theoretical working volume by a flow rate analysis for a single displacement chamber of the pump. This method becomes problematic to use when dealing with multiple working chambers, i.e., in real pumps or hydraulic motors. Therefore, this method will not be described in detail.

The value of $q_{t}$ is constant in the whole range of the motor operating parameters, that is, the speed $n$ and the pressure drop $\Delta p$ measured in the motor ports. In practice, the theoretical working volume $q_{t}$ is determined in a simplified way. The location of a flow meter (in the high-pressure line or in the low-pressure line of the motor) is not taken into account and it is assumed that the pressure drop $\Delta p$ in a motor is equal to the pressure drop $\Delta p_{i}$ in the working mechanism of this motor. Hence, the influence of liquid compressibility is neglected, as is the pressure drop $\Delta p_{i c h}$ in the internal channels of the motor.

The theoretical working volume $q_{t}$ is not the same as the geometric working volume $q_{g}$. The $q_{t}$ is obtained from experiment data (for $\Delta p$ tending to zero), but $q_{g}$ is mainly obtained (or calculated) from drawing documentations of the motor. The mathematical formulas for describing the geometric working volume $q_{g}$ are different for various types of positive displacement machines $[9,15]$. In addition, these formulas are derived with some simplifications for some types of pumps and motors. For example, the simplifications result in an error of up to $3 \%$ for gear machines $[7,15]$.

In addition, in the working mechanism of positive displacement machines, there are looseness and machining errors of the working mechanism components, assembly errors, changes in the machine temperature, etc. Furthermore, the pressure drop $\Delta p$ in the hydraulic motor is mainly a result of its torque load. In effect, the working chambers are resiliently deformed. Thus, in a loaded motor, the geometric working volume $q_{g}$ is different from the actual working volume $q_{r}$. Therefore, the geometric volume $q_{g}$ is not recommended for use to assess losses in positive displacement machines. It would be better to assume that the actual working volume $q_{r}$ assesses the volumetric and mechanical losses in a hydraulic motor. Then, $q_{r}$ should be expressed as a function of the pressure drop $\Delta p_{i}$ in the working chambers of the motor. Furthermore, the theoretical working volume $q_{t}$ and the geometric working volume $q_{r}$ should be determined taking into account the liquid compressibility. In addition to the precise determination of volumetric and mechanical losses with this approach, it is possible to more precisely assess the clearances of the components in the working mechanism of a hydraulic motor. Therefore, the development of a new methodology of determination of the theoretical working volume $q_{t}$ and the actual working volume $q_{r}$ of a hydraulic motor is appropriate and justified from the scientific and cognitive point of view. For this purpose, described in the following sections of the article are:

(a) known methods to determine the theoretical working volume;

(b) the proposed method of determining the theoretical $q_{t}$ and actual working volume $q_{r}$ (taking into account the effect of the flow meter position in the measurement system, the compressibility of liquid, and the pressure drop $\Delta p_{i c h}$ in the internal channel of a motor).

In this article the practical implementation of new methods is also presented. In order to confirm the correctness of the proposed new method of determining the $q_{t}$ and $q_{r}$, experimental tests of a hydraulic satellite motor were carried out, described and compared with Toet's and Balawender's methods. 


\section{Known Method to Determine the Theoretical Working Volume}

\subsection{Flow Rate in Hydraulic Motor}

Balawender and Toet have developed a practical method of determining the theoretical working volume $q_{t}$ of a hydraulic motor by using measurements of the liquid flow rate in the motor (Figure 1). According to them, making separate measurements for determining $q_{t}$ would unnecessarily extend the time of research and increase the costs [5-7].

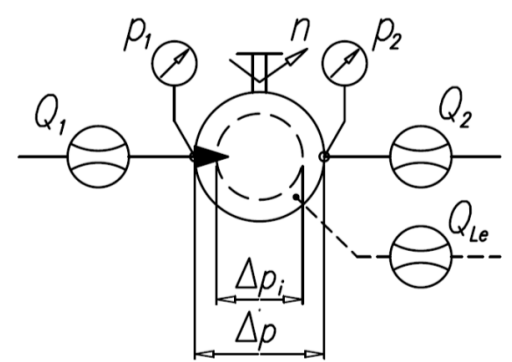

Figure 1. Symbol of hydraulic motor with measuring instruments: $Q_{1}, Q_{2}$ and $Q_{L e}$-flowmeters, $p_{1}$ and $p_{2}$-pressure gauges, $n$-speedometer, $\Delta p$-pressure drop in motor, $\Delta p_{i}$-pressure drop in motor working chambers.

According to Toet [6], the hydraulic motor input flow rate $Q_{1}$ is the volume flow delivered to the inlet port calculated at the inlet pressure $p_{1}$ and it uses the fluid temperature $T_{1}$ at the inlet port. Furthermore, the volume flow $Q_{1}$ through an averaging unit with a pressure difference $\Delta p$ at an inlet temperature $T_{1}$ and for a particular hydraulic oil is [6]:

$$
Q_{1}=Q_{g}+Q_{u}+Q_{C}+Q_{L}
$$

where:

- $Q_{g}$-the positive displacement component:

$$
Q_{g}=\underbrace{q_{g\left(\Delta p=0, T_{1}\right)} \cdot\left(1+K_{1} \cdot \Delta p\right)}_{q_{g}\left(\Delta p, T_{1}\right)} \cdot n
$$

- $\quad Q_{u}$-the liquid lifted in the gaps:

$$
Q_{u}=q_{u\left(\Delta p=0, T_{1}\right)} \cdot\left(n+K_{2} \cdot \Delta p\right)
$$

- $\quad q_{u}$-the liquid flow rate $Q_{u}$ per one revolution of the shaft at $\Delta p=0$;

- $Q_{C}$-the expansion/compression component (taken into account when the flow meter is located at the low-pressure side and the liquid is not aerated):

$$
\begin{gathered}
Q_{C}=q_{g\left(\Delta p=0, T_{1}\right)} \cdot\left(\frac{\rho_{o}}{\rho}-1\right) \cdot n \\
\frac{\rho_{o}}{\rho}-1=K_{3} \cdot \Delta p-K_{4} \cdot(\Delta p)^{2}+K_{5} \cdot(\Delta p)^{3}
\end{gathered}
$$

- $Q_{L}$-leakage in the working mechanism gaps;

- $\rho_{0}$-density at atmospheric pressure; 
- $\quad \rho$-density of liquid at pressure $p$;

- $K_{1}, K_{2}, K_{3}, K_{4}, K_{5}$ - constants.

According to Balawender, the flow rate in a hydraulic motor should be described by the following formulas $[7,8]$ :

$$
\begin{aligned}
& Q_{1}=Q_{g}+Q_{u}+Q_{k}+Q_{C, 1}+Q_{L i, 1}+Q_{L e, 1} \\
& Q_{2}=Q_{g}+Q_{u}+Q_{k}+Q_{C, 2}+Q_{L i, 2}+Q_{L e, 2}
\end{aligned}
$$

where $[7,8]$ :

$$
\begin{gathered}
Q_{g}=\underbrace{q_{g\left(\Delta p_{i}=0, T_{1}\right)} \cdot\left(1 \pm K_{6} \cdot \Delta p_{i}\right)}_{q_{g\left(\Delta p_{i}, T_{1}\right)}} \cdot(1+3 \cdot \alpha \cdot \Delta T) \cdot n \\
Q_{u}=q_{u\left(\Delta p_{i}=0, T_{1}\right)} \cdot\left(1 \pm K_{7} \cdot \Delta p_{i}\right) \cdot n
\end{gathered}
$$

- $Q_{k}$-the liquid flow rate caused by the cyclic elastic deformation of the working chambers $[7,8]$ :

$$
Q_{k}=\underbrace{K_{8} \cdot \Delta p_{i} \cdot q_{g\left(\Delta p_{1}=0, T_{1}\right)}}_{q_{k\left(\Delta p_{i}, T_{1}\right)}} \cdot n
$$

- $Q_{C, 1}$ - the flow rate caused by liquid compressibility at the moment of the working chamber transition from the emptying cycle to the filling cycle $[7,8]$ :

$$
Q_{C, 1}=\underbrace{\lambda \cdot \frac{\Delta p_{i}}{K_{s\left(\Delta p_{i}\right)}} \cdot q_{g\left(\Delta p_{i}>0, T_{1}\right)} \cdot n}_{q_{c, 1}}
$$

- $Q_{C, 2}$-the flow rate caused by liquid compressibility at the moment of the working chamber transition from the filling cycle to the emptying cycle $[7,8]$ :

$$
Q_{C, 2}=\underbrace{(1+\lambda) \cdot \frac{\Delta p_{i}}{K_{s\left(\Delta p_{i}\right)}} \cdot q_{g\left(\Delta p_{i}>0, T_{1}\right)} \cdot n}_{q_{c, 2}}
$$

- $Q_{L i, 1}$ and $Q_{L i, 2}$-the leakage from the high-pressure working chambers to the low-pressure working chambers (internal leakage) $[7,8]$ :

$$
Q_{L i, 1}+Q_{L i, 2}=Q_{L i}
$$

- $Q_{L e, 1}$ and $Q_{L e, 2}$-the leakage from the working chambers on the outside of the motor (external leakage from the motor body by the third hose) and $[7,8]$ :

$$
Q_{L e, 1}+Q_{L e, 2}=Q_{L e}
$$

- $\Delta p_{i}$-the pressure drop in the motor working chambers;

- $\quad \alpha$-the coefficient of linear expansion of materials of the motor working mechanism;

- $\Delta T$ - the increase in the motor temperature;

- $K_{6}, K_{7}, K_{8}$-constants;

- $K_{s}$-the isentropic secant modulus of liquid compressibility;

- $\lambda$-the relative harmful volume. 


\subsection{Theoretical Working Volume from the Method Defined in ISO 8426}

The method defined in ISO 8426 uses measurement of the flow rate $Q_{1}$ at different speeds $\mathrm{n}$ at a constant pressure and a constant input fluid temperature. The theoretical working volume can be determined by [13]:

$$
q_{t}=\frac{Q_{1(2)}-Q_{1(1)}}{n_{(2)}-n_{(1)}}
$$

The $q_{t}$ determined according to the above formula changes while measuring along multiple pressure differences. This makes the theoretical working volume calculation inaccurate.

\subsection{Toet's Method}

After analysis of the partial derivative of the flow $Q_{1}$ (expressed by the Formula (1)) after the speed $n\left(\frac{\partial Q_{1}}{\partial n}\right)$, Toet concluded that the theoretical working volume $q_{t}$ of the motor should be described in the following form [6]:

$$
q_{t}=\left(\frac{\partial Q_{1}}{\partial n}\right)_{\left(\Delta p=0, T_{1}\right)}=\left(\frac{Q_{1}}{n}\right)_{\left(\Delta p=0, T_{1}\right)}=q_{g\left(\Delta p=0, T_{1}\right)}+q_{u\left(\Delta p=0, T_{1}\right)}
$$

where $q_{u}$ is the volume of liquid per one revolution of the shaft caused by the relative velocities between two surfaces of clearances in the working mechanism.

According to Toet [6]:

(a) $q_{t}$ is independent of $n$ and $\Delta p$;

(b) besides $q_{g\left(\Delta p=0, T_{1}\right)}$ and $q_{u\left(\Delta p=0, T_{1}\right)}$ the other effects (not expressed by formulas) have influence on the leakage $Q_{L}$;

(c) there is no way for separation of $q_{g}$ and $q_{u}$;

(d) if the volumetric efficiency is greater than $100 \%$ then only the $q_{g}$ was applied (omitting the $q_{u}$ );

(e) for some types of positive displacement machines (screw pumps and motors), where $q_{g}$ is very precisely determinable and $q_{u} \approx 0$ is $q_{g\left(\Delta p=0, T_{1}\right)} \approx q_{t}$ (for the same of $T_{1}$ ).

According to Toet, the flow rate $Q$ in a hydraulic motor is described by the linear function [6]:

$$
Q_{(\Delta p=c o n s t)}=A_{i} \cdot n+B_{i}
$$

where

$$
A_{i}=\left(\frac{\partial Q}{\partial n}\right)_{(\Delta p=c o n s t)}
$$

and $B$ is the leakage flow in the motor for $\Delta p=0$. The characteristics of $Q$ for different constant values of $\Delta p$ are shown in Figure 2. However, the relationship

$$
A=a \cdot \Delta p+q_{t}
$$

is determined from the values $A_{1}, A_{2}, A_{3}, \ldots, A_{\mathrm{n}}$ (Figure 3). Hence, $q_{t}$ is the theoretical working volume of the hydraulic motor supplied with oil at temperature $T_{1}$ measured in the inflow port of the motor [6]. 


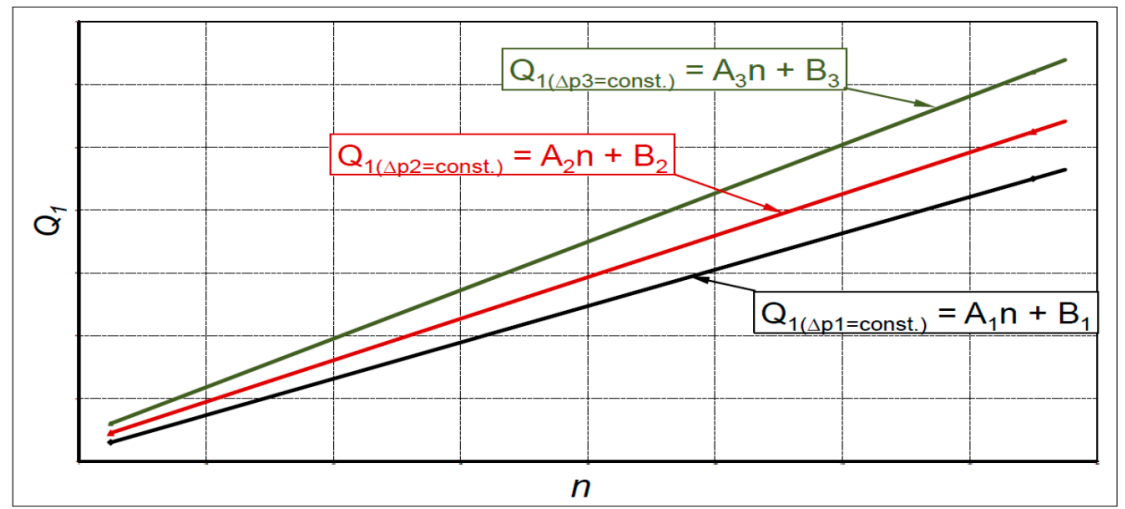

Figure 2. Linear interrelationship between motor input flow rate $Q_{1}$ and shaft speed $n$ [6].

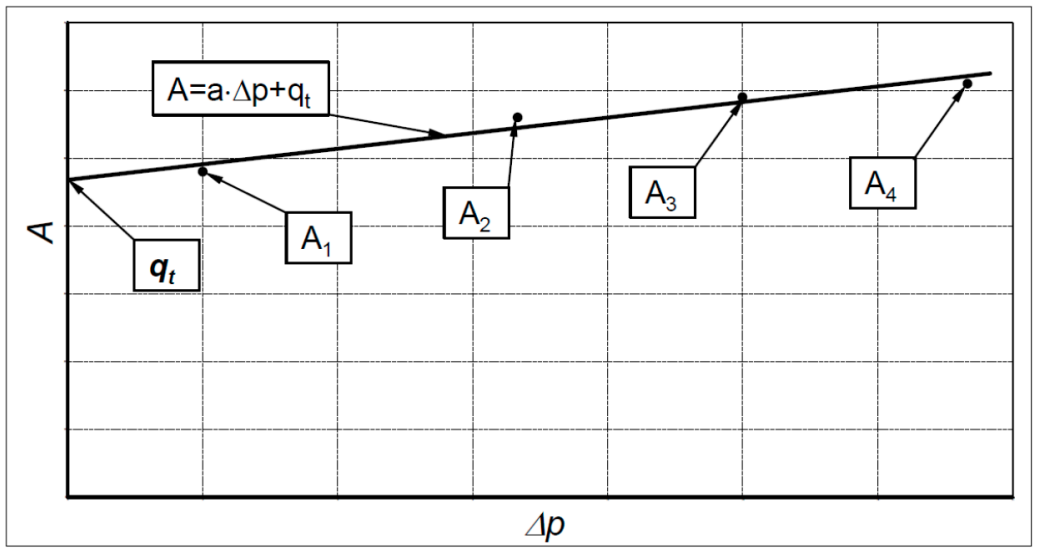

Figure 3. Working volume $A$ vs. pressure difference $\Delta p$ for a hydraulic motor [6].

Furthermore, Toet claims that the linear relationship between $A$ and $\Delta p$ is recommended with the correlation coefficient of at least 0.9 . Nonlinear fitting is recommended for smaller values of correlation coefficient [6].

\subsection{Balawender's Method}

In 1974, Balawender noticed the shortcomings of Toet's method and described them in [7]. Balawender's notes are still valid, although they were omitted by Toet in [6]. Balawender claimed that the method indicated by Toet is inaccurate, because [7]:

- The notation of the theoretical working volume given by Equation (16) is incorrect as it suggests a measurement at $\Delta p=0$. In real conditions, the motor does not run at $\Delta p=0$;

- In fact, in order to determine the theoretical working volume $q_{t}$ the limit values of the working volume for the internal pressure drop $\Delta p_{i}$ going to zero should be taken into account;

- The function $\frac{\partial Q}{\partial n}$ can be unspecified in the mathematical sense at $\Delta p=0$ due to the unspecified displacements of the motor working mechanism elements;

- The flow component caused by the compressibility of liquid was incorrectly interpreted.

Balawender concluded that the theoretical working volume $q_{t}$ of the motor should be described in the following form $[7,8]$ :

$$
q_{t}=\lim _{\Delta p_{i} \rightarrow 0} q_{g\left(\Delta p_{i}\right)}+\lim _{\Delta p_{i} \rightarrow 0} q_{u\left(\Delta p_{i}\right)}
$$

Balawender, similarly to Toet, claims that:

(a) $q t$ is independent of $n$ and $\Delta p$; 
(b) the temperature of liquid can have influence on $q t$,

(c) there is no way for of $q g$ and $q u$.

Furthermore, Balawender simplifies the problem by taking $\Delta p_{i} \approx \Delta p$. The linear relationship between $A$ and $\Delta p$ and between $B$ and $\Delta p$ is recommended (Figure 4) $[7,8]$.

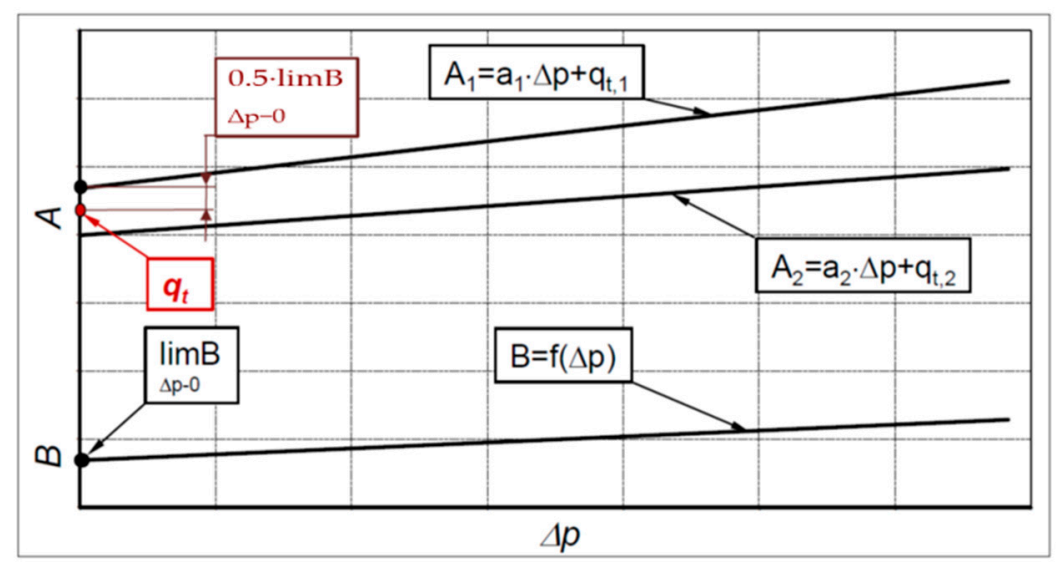

Figure 4. Working volume $A$ and leakage $B$ vs. pressure difference $\Delta p$ for hydraulic motor $[7,8]$.

According to Balawender, the theoretical working volume is described as $[7,8]$ :

$$
q_{t, 1}=\lim _{\Delta p \rightarrow 0} A_{1(\Delta p)}-\frac{1}{2} \cdot \lim _{\Delta p \rightarrow 0} Q_{L e(\Delta p)}
$$

or

$$
q_{t, 2}=\lim _{\Delta p \rightarrow 0} A_{2(\Delta p)}+\frac{1}{2} \cdot \lim _{\Delta p \rightarrow 0} Q_{L e}(\Delta p)
$$

Finally, the theoretical working volume should be calculated as $[7,8]$ :

$$
q_{t, 1}=\frac{q_{t, 1}+q_{t, 2}}{2}
$$

Balawender recommends to test the motor in the following speed range:

$$
n_{\max } \leq 3 \cdot n_{\min }
$$

where the $n_{\min }$ is the minimum speed at which the motor can work stably. The limitation of the maximum speed results from the assumption $\Delta p_{i} \approx \Delta p$.

\section{New Method of Determining the Theoretical and Actual Working Volume}

\subsection{The Flow Rate Caused by Liquid Lifting in Gaps}

Both Toet and Balawender point to the component $Q_{u}$ of the flow rate. According to them $Q_{u}$ has an impact on the theoretical working volume $q_{t}$. However, it should be noted that this does not apply to all displacement machines. For example, in the working mechanism of piston machines, the walls of the gaps move with a reciprocating movement. However, in satellite and gear machines, they move in a rotational movement. Thus, in piston machines the direction of flow $Q_{u}$ in the gap between the piston and the cylinder varies with the direction of the piston movement. In satellite machines, the satellite rotates and there is a flow from the low-pressure chamber into the high-pressure chamber on one side, and there is also a flow of the same value but in the opposite direction on the other side. Thus, the flow $Q_{u}$ should not occur in the overall balance [16]. Nevertheless, it is proposed to include the flow per one revolution of shaft $q_{u}$ in the theoretical working volume according to Formula (22). 


\subsection{The Actual Working Volume $q_{r}$}

During the tests on a prototype of an axial piston pump, Osiecki noted that the value of the mechanical-pressure efficiency exceeded $100 \%$ (with correct pressure and torque measurements). Obviously, he considered it absurd [17]. After an in-depth analysis of the pump structure, Osiecki showed that the pump was characterized by low stiffness of elements, especially the shaft. As a result, with increasing the load of the pump the working volume of the pump also increased. Thus, it can be seen that the adoption of the theoretical working volume $q_{t}$ can introduce a significant error in the evaluation of the losses in displacement machines. Therefore, it is necessary to take the actual working volume $q_{r}$ (as a function of pressure in working chambers) to calculate the losses in the machine.

Both Balawender and Toet in their considerations assumed that the geometric working volume $q_{g(\Delta p, T 1)}$ is a linear function of pressure (see Formulas (4) and (10)). This is a simplification, of course. It should be noted that the working chambers of displacement machines have a finite volume $V$. This volume can be described in the general form with three dimensions $x, y, z$ (at $p=0)$ :

$$
V_{(p=0)}=x \cdot y \cdot z
$$

As a result of increasing the pressure (i.e., for $p>0$ ) the values of these dimensions change by $\Delta x$, $\Delta y$ and $\Delta z$, respectively, and the actual volume $V_{(p)}$ is a non-linear function of pressure:

$$
V_{(p)}=V_{(p=0)}+\underbrace{f\left(p^{3}\right)+f\left(p^{2}\right)+f(p)}_{\Delta V_{(p)}}
$$

The above dependence can be referred to as a displacement machine, which is a hydraulic motor. It should be noted that the deformation values $\Delta x, \Delta y$ and $\Delta z$ can be positive or negative. For example, in gear hydraulic motors not equipped with an axial clearance compensation unit, the distance between the closing plates of the toothed gear increases with the increasing of $\Delta p_{i}$, that is, $\Delta z>0$. However, in such a motor with an axial clearance compensation unit, there may be a reduction in the clearance value, that is, $\Delta z<0$. Another phenomenon is the cyclic elastic deformation of the gears cooperating with each other. This causes a cyclic change in the volume of the working chamber. Due to the same nature of the phenomenon, volumes $q_{g}$ and $q_{k}$, described by Balawender with Formulas (10) and (12), are proposed to be presented by one mathematical formula with a structure such as (28):

$$
q_{g\left(\Delta p_{i}\right)}+q_{k\left(\Delta p_{i}\right)}=q_{g\left(\Delta p_{i}=0\right)} \underbrace{f}_{\Delta q_{g\left(\Delta p_{i}\right)} f\left(\Delta p_{i}{ }^{3}\right) \pm f\left(\Delta p_{i}{ }^{2}\right) \pm f\left(\Delta p_{i}\right)}=q_{r}
$$

where $q_{r}$ is the actual working volume of a loaded motor. The value of $q_{r}$ can be determined experimentally, provided that the component flow rate $Q_{C}$ caused by liquid compressibility is eliminated. This can be done by taking into account the influence of compressibility of the liquid on the flow rate measured by the flow meter.

\subsection{The Effect of the Flow Meter Position in the Measurement System on the Actual Working Volume Value}

In his method, Toet recommends the placing of a flow meter in the inlet line to a hydraulic motor. In this arrangement, the flow meter measures the total flow including external leakage. However, Toet has omitted the effect of outside leakage on the theoretical working volume.

However, for the case of placing the flow meter in the low-pressure line, Toet introduces the influence of the liquid compressibility on the flow rate, expressed by Formula (4). Therefore, it is only the influence of the liquid compressibility related to the geometric working volume $q_{g}$. Thus, Toet neglects the influence of liquid compressibility on the leakage flow rate $Q_{L}$. This is a serious 
inaccuracy. Hence, according to Toet, for a flow meter located in the outflow line, the calculation of the theoretical working volume should be made according to the following formula:

$$
Q_{\left(p_{1}\right)}=Q_{2}+Q_{C}
$$

where $Q_{c}$ is expressed by Formula (4). Therefore, the theoretical working volume $q_{t}$ will be calculated with an error.

According to Balawender, the compressibility of the liquid has an effect on the value of the flow rate in a motor measured by a flow meter. Namely, the location of the flow meter in the measuring system is important. If the flow meter is located in a high-pressure line of the motor, then [7]:

$$
Q_{\left(p_{1}\right)} \approx Q_{1}
$$

However, if the flow meter is located in the low-pressure line of the motor, then [7]:

$$
Q_{\left(p_{1}\right)}=\kappa \cdot Q_{2}
$$

In the above equations, $k$ is the correction coefficient that removes the systematic error in measuring the flow rate caused by the liquid compressibility and its thermal expansion. The coefficient $k$ is a function of the liquid temperature, the content of air not dissolved in liquid $\left(X_{o}\right)$ and the increase in the liquid pressure $\Delta p$. For oil and for $X_{o}=0.01$ and $t=40^{\circ} \mathrm{C}$ the coefficient is:

$$
\kappa=0.97-75 \cdot 10^{-5} \cdot \Delta p
$$

where $\Delta p$ is expressed in [MPa].

In both cases, Balawender used an additional flow meter for measuring the external leakage (like in Figure 1).

Therefore, in both Toet's and Balawender's methods, the effect of the flow meter location in the measuring system is simplified. In order to more accurately calculate the flow rate related to the pressure in the high-pressure working chamber, the following method is proposed. The flow meter located in the inlet line to the motor measures the flow rate $Q_{1}$ of the liquid compressed to the pressure $p_{1}$ (Figure 1). The working chamber filling process is from the chamber minimum volume $V_{\min }$ to the chamber maximum volume $V_{\max }$. The pressure in this chamber is lower than the pressure $p_{1}$ by the pressure drop $\Delta p_{\text {ich } 1}$ in the internal inflow channel (Figure 5). Therefore, taking into consideration the compressibility of the liquid, the flow rate $\mathrm{Q}_{(p H)}$ related to the pressure $p_{\mathrm{H}}$ in the high-pressure working chamber will be:

$$
Q_{\left(p_{H}\right)}=Q_{1}+\Delta Q_{1}
$$

where $\Delta Q_{1}$ is an additional flow rate resulting from the expansion from pressure $p_{1}$ to pressure $p_{\mathrm{H}}$. It is necessary to add, that in this case the calculated value of $Q_{(p H)}$ is the sum of the theoretical flow rate $Q_{t}$ in the motor and the internal $Q_{L i}$ and external $Q_{L e}$ leakages. Thus, this method of measurement does not allow calculating the actual working volume $q_{r}$ of the motor.

The flow meter located in the outflow line of the motor measures the flow rate $Q_{2}$ of liquid decompressed from pressure $p_{H}$ to pressure $p_{2}$ (Figure 1). Thus, the flow meter measures the following flow rate:

$$
Q_{2}=Q_{\left(p_{H}\right)}+\Delta Q_{2}
$$

where $\Delta Q_{2}$ is an additional flow rate caused by liquid decompression from pressure $p_{H}$ to pressure $p_{2}$. It is necessary to add, that in this case the calculated value of $Q_{(p H)}$ is the sum of the theoretical flow rate $Q_{t}$ and the internal leakage $Q_{L i}$.

The value of $Q_{(p H)}$, calculated from Formula (34) or (35) should be taken for the correct calculation of the theoretical working volume $q_{t}$. It is possible to calculate both $\Delta Q_{1}$ and $\Delta Q_{2}$ if the bulk modulus $K$ of the liquid is known. In real conditions, the working fluid is somewhat aerated. Thus, the content 
of the non-dissolved air in the oil affects the bulk modulus $K$. The tangential isentropic bulk modulus $K_{Z(p)}$ is very well described by the Zaluski formula [18]:

$$
K_{Z(p)}=\frac{e^{\left(\frac{p_{o}-p}{K}\right)} \cdot\left\lfloor 1+m \cdot \frac{p-p_{o}}{K}\right\rfloor^{\left(-\frac{1}{m}\right)}+\frac{X_{o}}{1-X_{o}} \cdot\left(\frac{p_{o}}{p}\right)^{\left(\frac{1}{n}\right)}}{\frac{e^{\left(\frac{p_{o}-p}{K}\right)}}{K} \cdot\left\lfloor 1+m \cdot \frac{p-p_{o}}{K}\right\rfloor^{\left(\frac{1-m}{m}\right)}+\frac{X_{o}}{n \cdot p_{0} \cdot\left(1-X_{0}\right)} \cdot\left(\frac{p_{o}}{p}\right)^{\left(\frac{1+n}{n}\right)}}
$$

where:

- $\quad K$-the bulk modulus of non-aerated oil at atmospheric pressure $p_{o}$;

- $X_{0}$-the amount of non-dissolved air in the oil at atmospheric pressure $p_{0}$;

- $\quad p$-the absolute pressure;

- $n$-the polytrophic exponent;

- $\quad m$-the coefficient of the influence of pressure $p$ on the bulk modulus $K$.

It follows from the basic definition of the bulk modulus that the change in the volume $\Delta V_{(p 2)}$ of liquid from pressure $p_{0}$ to $p_{2}$ is:

$$
\Delta V_{\left(p_{2}\right)}=-\int_{p_{o}}^{p_{2}} \frac{V_{o}}{K_{Z(p)}} \cdot \partial p
$$

where $V_{o}$ is the initial volume. Similarly, the change of the volume $\Delta V_{(p H)}$ of the liquid from pressure $p_{o}$ to pressure $p_{H}$ in the filled working chamber will be:

$$
\Delta V_{\left(p_{H}\right)}=-\int_{p_{o}}^{p_{H}} \frac{V_{o}}{K_{Z(p)}} \cdot \partial p
$$

From the practical point of view, the volume of the flow meter chamber can be assumed as the initial volume $V_{0}$. Thus, the volume of liquid measured by the flow meter at a pressure $p_{2}$ and related to pressure $p_{0}$ is:

$$
Q_{o}=Q_{2}+\frac{\Delta V_{\left(p_{2}\right)}}{\Delta t}
$$

where $\Delta t$ is the time of the flow meter chamber filling at the flow rate $Q_{2}$. However, the flow rate related to the pressure $p_{H}$ is:

$$
Q_{\left(p_{H}\right)}=Q_{o}-\frac{\Delta V_{\left(p_{H}\right)}}{\Delta t}=Q_{2}+\frac{\Delta V_{\left(p_{2}\right)}-\Delta V_{\left(p_{H}\right)}}{\Delta t}
$$

The values of $Q_{(p H)}$ calculated according to Formula (40) are required for determining the characteristics $Q_{(p H)}=\mathrm{f}\left(\Delta p_{i}\right)$. It is assumed that these characteristics are linear and therefore it is proposed to describe them with a linear equation, as in Formula (19).

\subsection{Method of Pressure Drop Measurement in Motor Internal Channels}

In a hydraulic motor with variable shaft rotation directions, the inflow and outflow internal channels have the same shape and dimensions. Thus, it is only necessary to measure the pressure drop $\Delta p_{i c 1}$ in the inflow internal channel and the pressure drop $\Delta p_{i c h}$ in the motor, which are calculated according to the formula [16]:

$$
\Delta p_{i c h}=2 \cdot \Delta p_{i c h 1}
$$

where:

$$
\Delta p_{i c h 1}=p_{1}-p_{H}
$$

The idea of the measured system is shown in Figure 5. The tested hydraulic motor 1 works as a pump and is driven by an electric motor 2 . The speed $n$ of the electric motor 2 and machine 1 is set via a frequency converter. In this method, the measurement data acquisition system records: 
(a) the pressure $p_{1}$ in the motor port;

(b) the pressure $p_{H}$ in the motor working chamber;

(c) the motor output flow rate $Q_{2}$;

(d) the rotational speed $n$ of the motor shaft.

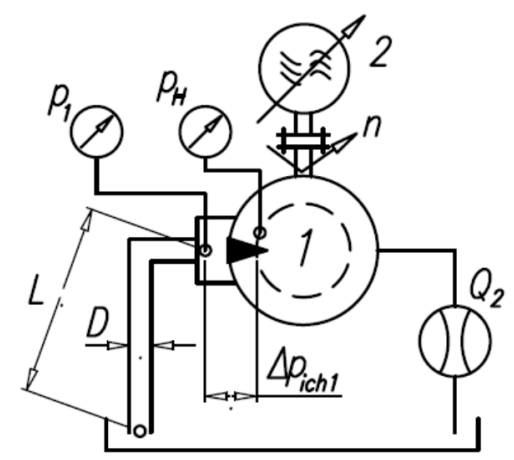

Figure 5. Diagram of the hydraulic circuit of the test stand for measuring the pressure drop in the internal channel of a hydraulic motor [16]: $D$ and $L$ - suction tube diameter and length, respectively, 1 -tested motor, 2 - electric motor controlled by a frequency converter, $Q_{2}$ - flow meter, $n$-rotational speed, $p_{L P C}$ - pressure in the low-pressure working chamber, $p_{1}$ - pressure in the motor inflow port, $\Delta p_{i c h 1}$ - pressure drop in the high-pressure internal channel of the motor.

The pressure losses in the motor internal channels can be described by [16]:

$$
\Delta p_{i c h}=C_{t} \cdot \rho \cdot Q_{2}^{2}+C_{l} \cdot v \cdot \rho \cdot Q_{2}
$$

where:

- $\quad C_{t}$ - the constant of the turbulent flow component;

- $C_{l}$-the constant of the laminar flow component;

- $v$-the kinematic viscosity;

- $\rho$-the density of liquid.

\subsection{Model of Flow Rate in Hydraulic Motor}

Taking into account the liquid compressibility (the influence of the flow meter location in the measurement system) and the fact that the leakages in the motor and the deformation of the working chamber are determined by the pressure drop $\Delta p_{i}$ in the working chambers, the flow rate $Q_{(p H)}$ in the motor should be described by the following formula:

$$
Q_{\left(p_{H}, \Delta p_{i}=\text { const }\right)}=A_{\left(p_{H}\right)} \cdot n+B_{\left(p_{H}\right)}
$$

\subsection{Practical Implementation of the Method}

In order to determine the theoretical and actual working volume, it is necessary (step by step):

(a) To measure the flow $Q_{1}$ or $Q_{2}$ at a constant inlet temperature $T_{1}$ and a constant pressure drop $\Delta p$ for several values of $n$ (no less than five). The measurement has to be taken once again using at least five different pressure drops $\Delta p$;

(b) To measure the pressure drop $\Delta p_{\text {ich }}$ in the internal channel of the motor according to the method described in Section 3.4;

(c) To calculate the pressure drop $\Delta p_{i}$ in the working chamber of the motor for data from item (a);

(d) If the flow meter is located in the low-pressure line, the influence of the liquid compressibility should be taken into account and the flow rate $Q_{(p H)}$ corresponding the value of high-pressure $p_{H}$ in the working chamber should be calculated; 
(e) To plot the characteristics $Q_{(p H)}=\mathrm{f}(n)_{\Delta \mathrm{pi}=\text { const }}$ and calculate the coefficients $A$ in the Formula (17).

\section{Results of Experimental Research}

\subsection{Tested Motor}

The general view and design of the prototype of hydraulics satellite motor (used in the experimental tests) is presented in Figure 6. The working mechanism of the satellite motor is presented in Figure 7. The revolving motion of rotor $R$ is done by satellites $S$. The satellites $S$ are in gear with the curvature $C$ and the rotor $R$ and, in the same, form the working chambers (numbers from 1 to 10 in Figure 7).
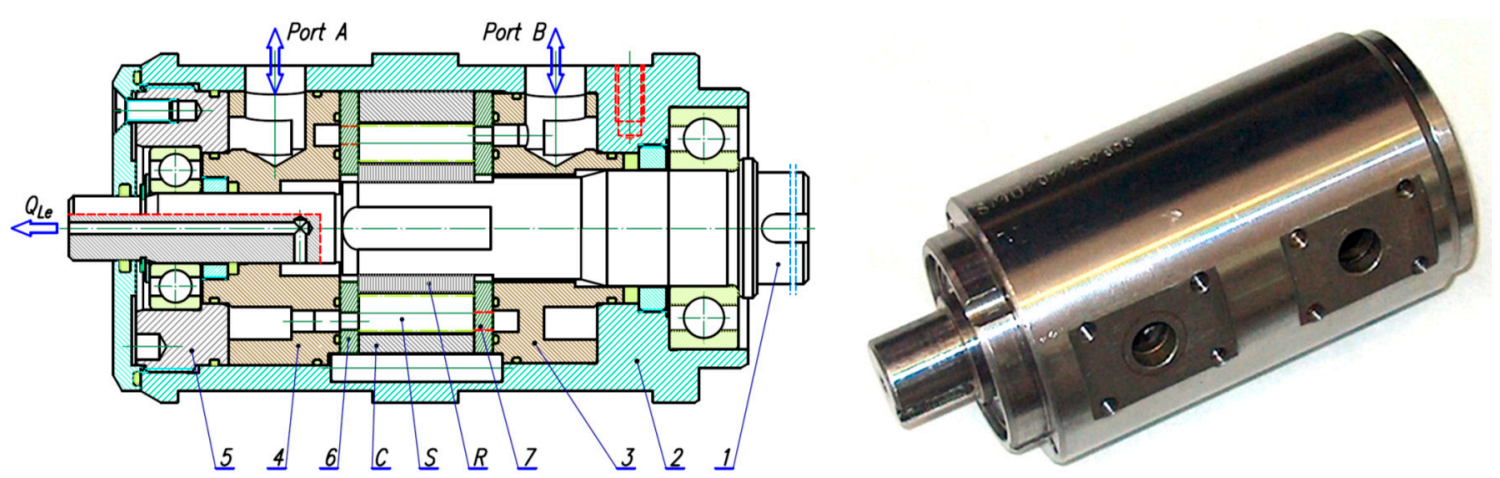

Figure 6. Hydraulic satellite motor [16]: C-curvature (stator); $S$-satellite; $R$-rotor; 1 -shaft; 2-case; 3 and 4-inflow and outflow manifolds, respectively; 5 -rear body; 6 and 7-distribution (compensation) plates.

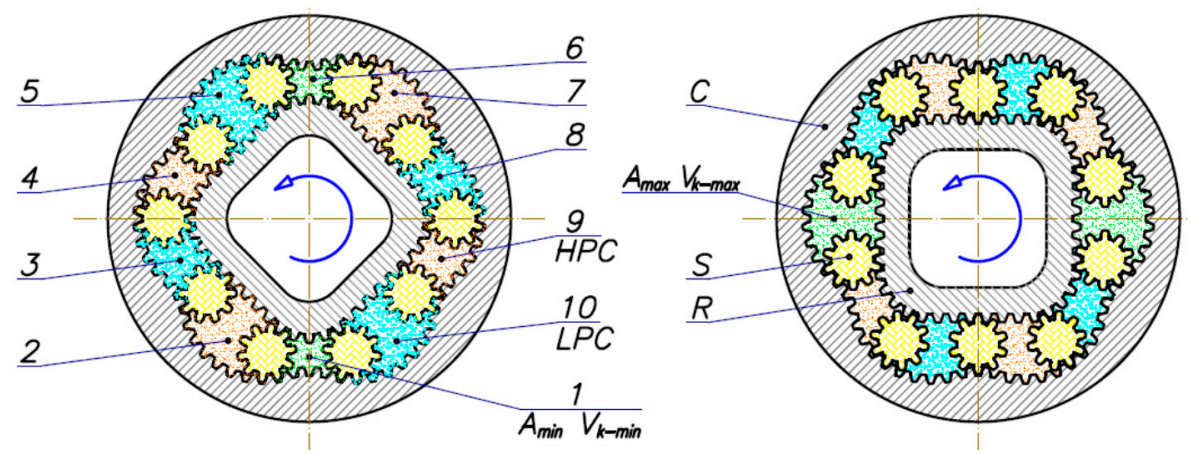

Figure 7. Satellite mechanism of type II [16,19-21]: C—curvature, $R$-rotor, $S$-satellite, $1-10$-working chambers, HPC - high pressure chambers, LPC - low pressure chambers, $V_{k \text {-min }}$-working chamber with minimum volume (dead chamber) and with minimum area $A_{\min }, V_{k-m a x}$-working chamber with maximum volume and with maximum area $A_{\max }$.

During rotation of the rotor $R$, the volume of working chamber increases from minimum $V_{k \text {-min }}$ to maximum $V_{k-\max }$ (the chamber is filled and is called the high-pressure chamber HPC), and next the volume of the working chamber decreases from $V_{k-\max }$ to $V_{k \text {-min }}$ and then the chamber is emptied (and is called a low-pressure chamber LPC).

In the presented satellite mechanism, 24 cycles of filling and emptying of the working chambers occur per one rotation of the shaft, that is $n_{C} \cdot n_{R}=24$, where $n_{R}$ and $n_{C}$ are the number of humps of the rotor and the curvature, respectively [16].

The compensation plates (Figure 6-elements 6 and 7), which are also called distribution plates, distribute the liquid to the working chambers and limit the leak in the gaps on the satellites and rotor faces, i.e., the plates deform elastically and thus limit the axial clearance of the rotor and the satellites. It is assumed that a reduction in the clearance can affect the theoretical working volume. 
The geometric working volume $q_{g}$ of the satellite mechanism is calculated according to the following formula [16]:

$$
q_{g}=n_{C} \cdot n_{R} \cdot H \cdot\left(A_{\max }-A_{\min }\right)
$$

The satellite motor used for the test had the following geometrical parameters (from CAD documentation):

- $\quad$ the height of the working mechanism $H=25 \mathrm{~mm}$;

- $\quad$ the minimum area of the working chamber $A_{\min }=26.11 \mathrm{~mm}^{2}$;

- the maximum area of the working chamber $A_{\max }=83.51 \mathrm{~mm}^{2}$.

- Thus, the geometric working volume of the satellite mechanism was $q_{g}=34.44 \mathrm{~cm}^{3} / \mathrm{rev}$. Other motor parameters were:

- $\quad$ the tooth module $m=0.75 \mathrm{~mm}$;

- the difference in the height of the satellites and the rotor in relations to the curvature was $\Delta h=$ $5 \mu \mathrm{m}$.

\subsection{The Test Stand and Measuring Apparatus}

The general view of the test stand and the diagram of the measurement system of this test stand is shown in Figure 8. The test stand was set up with power recuperation.
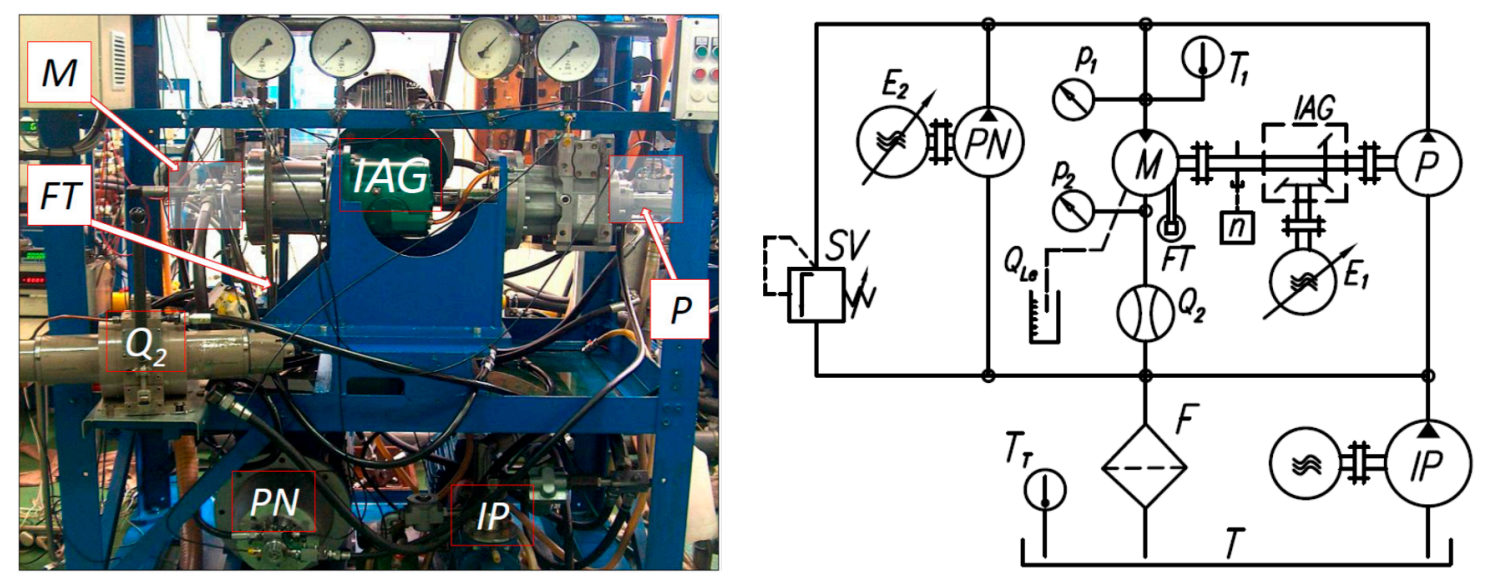

Figure 8. Diagram of the test stand measurement system [21]: $P$-pump, $M$-tested hydraulic motor, $P N$-pump for filling leaks in $P$ and $M, I P$-impeller pump (pre-supply pomp), $S V$-safety valve, $F$-filter, $T$-reservoir, $I A G$-intersecting axis gear, $\mathrm{E}_{1}$ and $\mathrm{E}_{2}$ - electric motors with frequency converters, $\mathrm{T}_{1}, \mathrm{~T}_{\mathrm{T}}$-temperature sensors, $Q_{2}$-flowmeter, $Q_{\mathrm{Le}}$-leakage measurement, FT-force transducer (torque measurement), $\mathrm{n}$-inductive sensor (rotational speed measurement).

During the test of the motor, the following parameters were measured:

- $\quad$ pressure $p_{1}$ in the inflow port (strain gauge pressure transducer, range 0-10 MPa and 0-40MPa, class 0.3 ;

- $\quad$ pressure $p_{2}$ in the outflow port (strain gauge pressure transducers, range 0-2.5 MPa, class 0.3);

- flow rate $Q_{2}$ (piston flowmeter, the flowmeter chamber volume $0.63 \mathrm{dm}^{3}$, range $0-200 \mathrm{~L} / \mathrm{min}$, class 0.2 , accuracy of reading $0.01 \mathrm{~L} / \mathrm{min}$, maximum measurement error $0.41 \mathrm{~L} / \mathrm{min}$ );

- torque $M$ (strain gauge force transducer FT mounted on the arm $0.5 \mathrm{~m}$ (the arm attached to the motor body), range $0-100 \mathrm{~N}$, class 0.1 );

- $\quad$ rotational speed of shaft $n$ (inductive sensor, accuracy of measurement $\pm 0.01 \mathrm{rpm}$ );

- temperature $T_{1}$ of liquid in the inflow port of the motor (RTD temperature sensor, class A, max. measurement error $0.5^{\circ} \mathrm{C}$ ). 
In order to determine the working volume of the motor from the experimental data with the smallest possible error, it was very important to maintain the setting of speed $n$, pressure drop $\Delta p$ and liquid temperature $T_{1}$ with the least possible deviation. Thus:

- $\quad$ the rotational speed $n$ was maintained with a deviation of $\pm 0.1 \mathrm{rpm}$;

- the pressure drop $\Delta p$ was maintained with a deviation of $\pm 0.05 \mathrm{MPa}$;

- the temperature in inflow port $T_{1}$ was maintained with a deviation of $\pm 1.0^{\circ} \mathrm{C}$.

Due to the large chamber of the piston flowmeter $\left(0.63 \mathrm{dm}^{3}\right)$, the shaft of the tested motor had to make about 18 rotations in order to obtain the flow rate measurement result. The piston flowmeter installed in the system measured the average value of the flow rate. This is a doubtless advantage. Furthermore, each recorded flow measurement result is the average of three measurements.

\subsection{Working Liquid Parameters}

The satellite motor was tested using the Total Azolla 46 oil with the temperature in the inflow port $T_{1}=43^{\circ} \mathrm{C}$ (kinematic viscosity $v=40 \mathrm{cSt}$, density $\rho=873 \mathrm{~kg} / \mathrm{m}^{3}$ ). Knowledge of the characteristics of the tangential isentropic bulk modulus $K_{Z(p)}$ of mineral oil is required for the proper determination of theoretical and actual working volume of a hydraulic motor (Figure 9). These characteristics were set by Załuski according to Formula (46) for the following data [17]:

- $\quad$ the bulk modulus of non-aerated oil at atmospheric pressure $K=1775 \mathrm{MPa}$;

- the content in oil of non-dissolved air at atmospheric pressure $X_{o}=0.01$;

- $\quad$ the politrophic exponent $n=1.4$;

- $\quad$ the coefficient of the effect of pressure $p$ on the bulk modulus $m=9.19$;

- $\quad$ the atmospheric pressure $p_{0}=0.1 \mathrm{MPa}$.

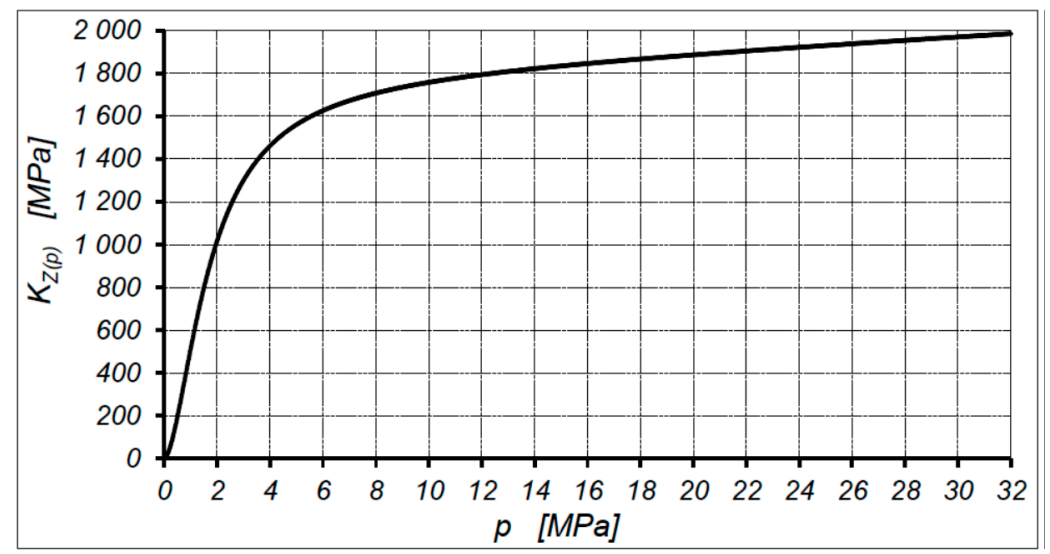

Figure 9. Tangential isentropic bulk modulus $K_{Z(p)}$ of Total Azolla mineral oil in the test stand [18].

For oil in the test stand and for $p>2 \mathrm{MPa}$ :

$$
\frac{\rho_{o}}{\rho}-1=-704.65 \cdot 10^{-6} \cdot \Delta p+726.32 \cdot 10^{-8} \cdot(\Delta p)^{2}-818.59 \cdot 10^{-10} \cdot(\Delta p)^{3}-826.5 \cdot 10^{-5}
$$

\subsection{Pressure Drop in Motor Internal Channels}

Based on the results of the experimental research carried out according to the method described in Section 3.4, the pressure drop $\Delta p_{i c h}$ in the motor internal channels can be described by the following empirical formula (according to (43)):

$$
\Delta p_{i c h}=0.003224 \cdot Q^{2}+0.02183 \cdot Q
$$


where $Q$ is measured in $[\mathrm{L} / \mathrm{min}]$ and $\Delta p_{i c h}$ in $[\mathrm{MPa}]$.

\subsection{Motor Output Flow Rate Characteristics}

The experimental test of the satellite motor was carried out in the rotational speed range $n=50$ $-1500 \mathrm{rpm}$. The characteristics $Q_{2}=\mathrm{f}(\mathrm{n})$ at $\Delta p=$ const. were determined in the entire speed range and in the speed range $n=50-150 \mathrm{rpm}$ (Figure 10). In order to maintain the clarity of the graphs, the characteristics are shown only for two extreme pressure drops in the motor, that is, for $\Delta p=2 \mathrm{MPa}$ and $\Delta p=32 \mathrm{MPa}$. The characteristics of $Q_{2}=\mathrm{f}(\mathrm{n})$ at other values of $\Delta p$ are described by equations and are presented in the Appendix A in Tables A1 and A2.
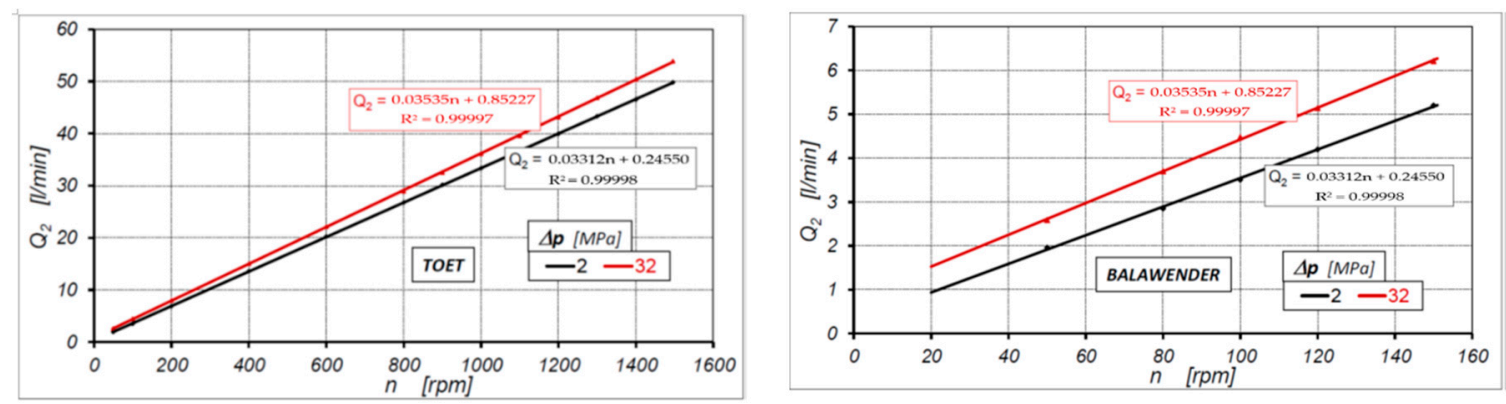

Figure 10. Characteristics of motor output flow rate $Q_{2}$ as a function of rotational speed $n$ at $\Delta p=$ const. On the left-Toet's method; on the right-Balawender's method.

The characteristics of external leakage $Q_{L e}$ in the tested motor are shown in Figure 11. It is the average value of leakages for the whole range of rotational speed $n$.

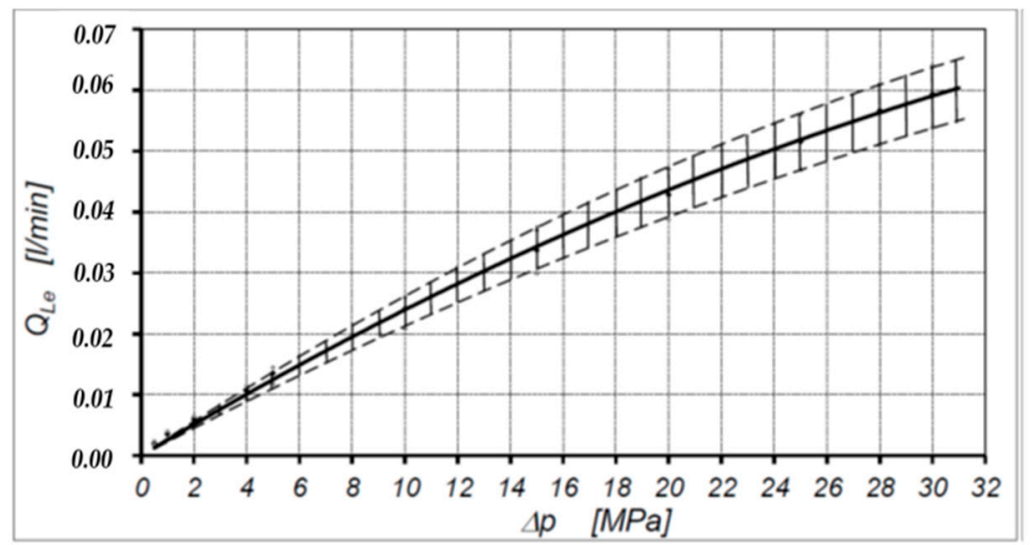

Figure 11. Characteristics of external leakage $Q_{L e}$ in the motor.

After taking into account the pressure drop $\Delta p_{i c h}$ in the internal channels of the motor, the characteristics of output flow rate $Q_{2}$ take the form like in Figure 12 (for $\Delta p_{i}=2 \mathrm{MPa}$ and $\left.\Delta p_{i}=32 \mathrm{MPa}\right)$. The influence of liquid compressibility was omitted. The characteristics for other $\Delta p_{i}$, omitting the liquid compressibility, are described by equations and presented in the Appendix $\mathrm{A}$ in Table A3. 


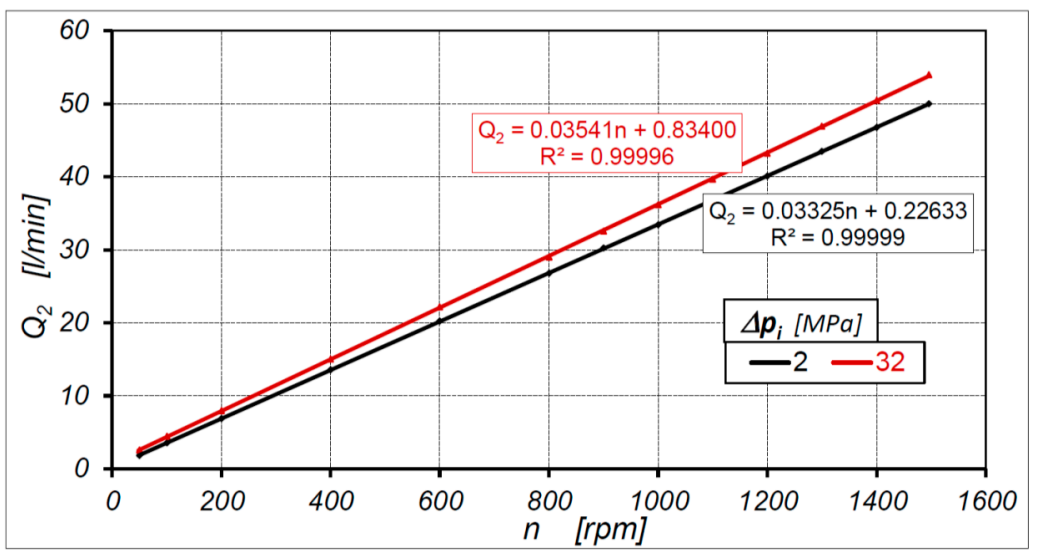

Figure 12. Characteristics of motor output flow rate $Q_{2}$ vs. rotational speed $n$ at $\Delta p_{i}=$ const. The influence of liquid compressibility is omitted.

The results of the flow rate measurements $Q_{2}$ (Figure 10) were corrected for the difference resulting from the compression of the oil to the supply pressure $p_{1}$-according to Formula (40) (Toet's method) and Formula (42) (Balawender's method). The characteristics presented in Figure 13 were obtained as a result. The characteristics of $Q_{(\mathrm{p} 1)}$ for other $\Delta p$ are described by equations and presented in the Appendix A in Tables A4 and A5.
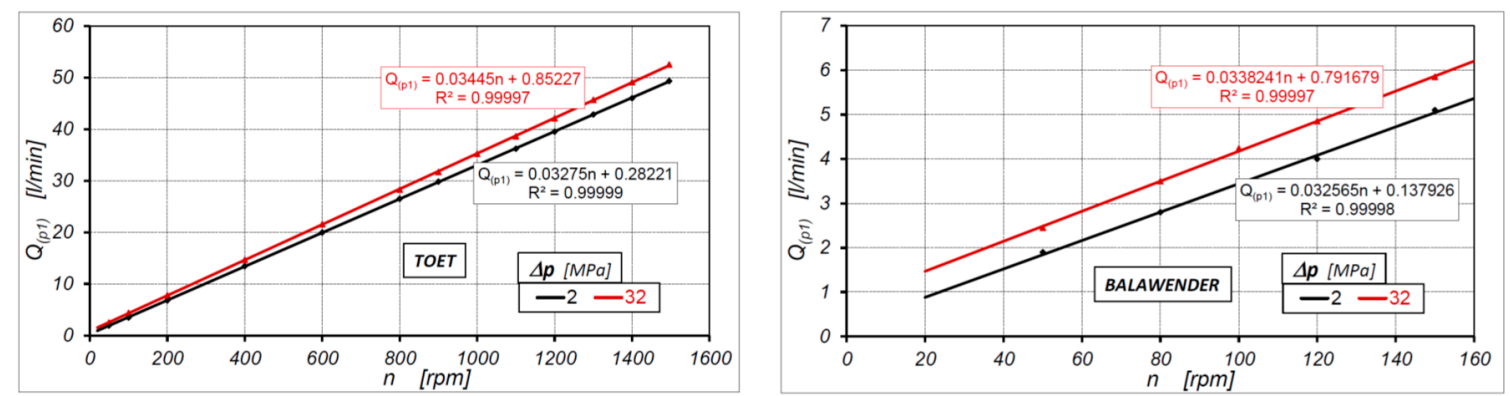

Figure 13. Characteristics of motor output flow rate $Q_{(\mathrm{p} 1)}$ related to pressure $p_{1}$ in the motor inflow port vs. rotational speed $n$ at $\Delta p=$ const. On the left-Toet's method; on the right-Balawender's method.

Using the method described in Section 3.3, the flow rate $Q_{(p H)}$ related to the pressure $p_{\mathrm{H}}$ in the high-pressure chamber of the motor was calculated, and the liquid compressibility was taken into account. The characteristics of $Q_{(p H, \Delta p i=c o n s t .)}=\mathrm{f}(\mathrm{n})$ for $\Delta p_{i}=2 \mathrm{MPa}$ and $\Delta p_{i}=32 \mathrm{MPa}$ are shown in Figure 14. The characteristics for other $\Delta p_{i}$ are described by equations and presented in the Appendix A in Table A6. 


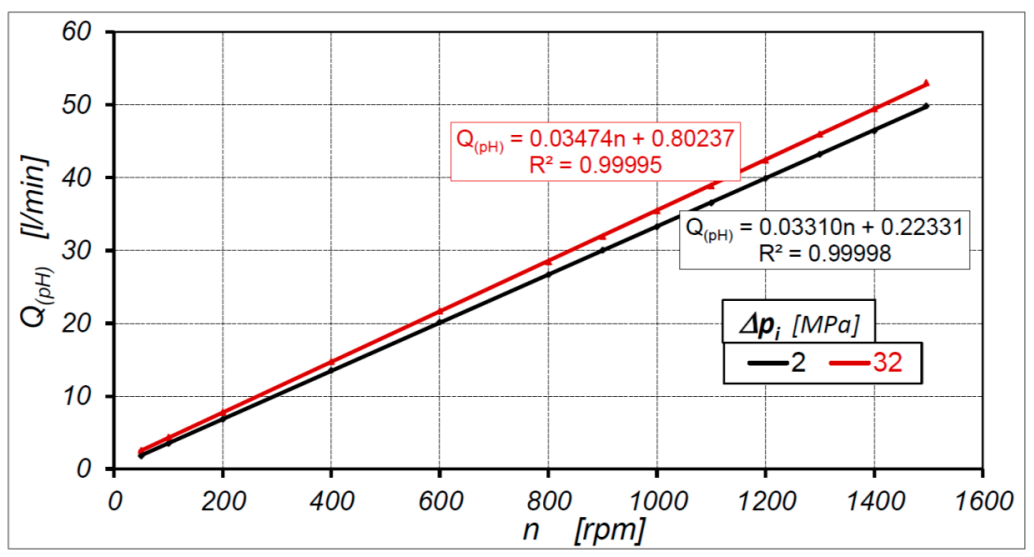

Figure 14. Characteristics of motor output flow rate $Q_{(p H)}$ related to the pressure in the high-pressure working chamber vs. rotational speed $n$ at $\Delta p_{i}=$ const.

\subsection{Motor Theoretical Working Volume According to Known Methods}

The working volume $A$ was calculated for two cases, omitting and including the influence of oil compressibility. The characteristics of $A=\mathrm{f}(\Delta p)$ determined according to Toet's and Balawender's method for both cases are presented in Figure 15. The characteristics of external leakage in the motor show, that $\lim _{\cdot p \rightarrow 0} Q_{L e(\cdot p)}=0$ (Figure 11). Thus, in Balawender's method, the external leakage does not affect the theoretical working volume $q_{t}$.
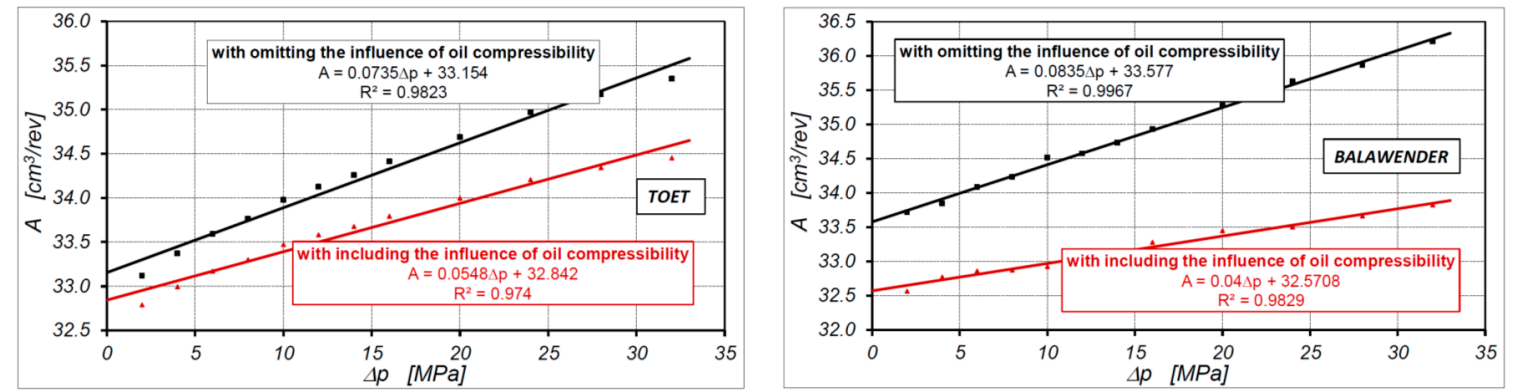

Figure 15. Characteristics of working volume $A$ vs. pressure drop $\Delta p$ in the motor. On the left-Toet's method; on the right-Balawender's method.

\subsection{Motor Theoretical Working Volume According to Proposed Method}

In Figure 16 are shown the characteristics $A=\mathrm{f}\left(\Delta p_{i}\right)$ of the working volume $A$ per one revolution of the shaft:

(a) determined taking into account the influence of oil compressibility;

(b) determined omitting the influence of oil compressibility. 


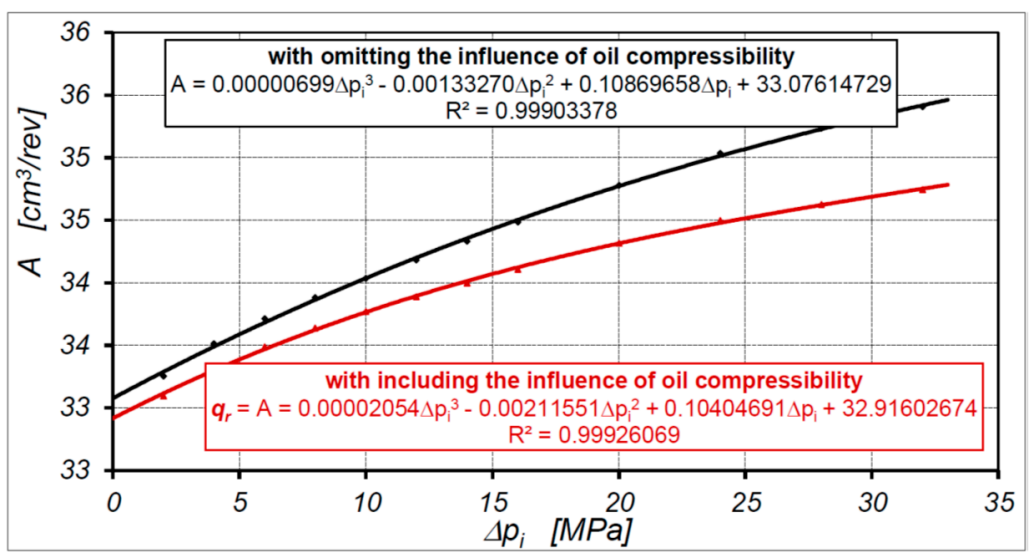

Figure 16. Characteristics of working volume $A$ vs. pressure drop $\Delta p_{\mathrm{i}}$ in the motor working chambers including and omitting the influence of oil compressibility.

The theoretical working volume $q_{t}$ of the motor determined by all the methods described above is shown in Table 1.

Table 1. Theoretical working volume $q_{t}$ of a satellie motor.

\begin{tabular}{ccc}
\hline & Method & $q_{t}\left[\mathrm{~cm}^{3} / \mathrm{rev}\right]$ \\
\hline & From project $-q_{g}$ & 34.440 \\
\hline \multirow{2}{*}{$\begin{array}{c}\text { Omitting the influence of oil } \\
\text { compressibility }\end{array}$} & Toet & 33.105 \\
\cline { 2 - 3 } & Balawender & 33.577 \\
\cline { 2 - 3 } $\begin{array}{c}\text { Including the influence of oil } \\
\text { compressibility }\end{array}$ & Proposed method & 33.076 \\
\cline { 2 - 3 } & Toet & 32.842 \\
\cline { 2 - 3 } & proposed method & 32.571 \\
\hline
\end{tabular}

\section{Discussion}

The results of the experimental research confirm that the following characteristics can be described by a linear function of the rotational speed $n$ :

(a) $Q_{2}=\mathrm{f}(\mathrm{n})_{\Delta \mathrm{p}=\text { const }}$ (Figure 10);

(b) $Q_{2}=\mathrm{f}(\mathrm{n})_{\Delta \text { pi }=\text { const }}$ (Figure 12);

(c) $Q_{(p H)}=\mathrm{f}(\mathrm{n})_{\Delta \mathrm{pi}=\text { const }}$ (Figure 14).

The value of the correlation coefficient $\mathrm{R}^{2}$ of the above-mentioned linear function is close to one $\left(R^{2}>0.999\right)$. Hence, the equations accurately describe the process of the fluid flow in the motor. Undoubtedly, the small scatter of the measurement results was mainly influenced by the piston flow meter. This flow meter measured the average flow rate corresponding to more than 18 revolutions of the motor shaft. Thus, the result indicated by the flow meter is the result of over 432 cycles of filling and emptying of the working chambers. Furthermore, very precise parameters were maintained during the tests, as described in Section 4.2.

The results of the experimental research confirm that, regardless of the method used, the theoretical working volume $q_{t}$ of a hydraulic motor is independent of its rotational speed $n$. However, the value of $q_{t}$ depends on the method used to calculate it (Table 1). Theoretical working volume $q_{t}$ calculated using Balawender's method differs up to $1.43 \%$ from $q_{t}$ calculated using Toet's method. This difference is not big. Nevertheless, it is difficult to indicate a more reliable result because both Toet's method and Balawender's method contain simplifications (described in Sections 3.3 and 3.4). 
Nonetheless, $q_{t}$ calculated using the new method (taking into account the pressure drop in the motor internal channels, the flowmeter position in the measurement system and the influence of oil compressibility) is about $1.06 \%$ larger than $q_{t}$ calculated using Balawender's method and is about $0.22 \%$ larger than $q_{t}$ calculated using Toet's method (Table 1 ). These differences are also not big. It is assumed that one of the main reasons for such small differences in the results may be the low pressure drop $\Delta p_{\mathrm{i}}$ in the motor internal channels. In addition, for this motor, simplified calculations of the effect of liquid compressibility on the flow rate (according to Toet's and Balawender's methods) do not have, as can be seen, any greater impact on the theoretical working volume $q_{t}$.

Omitting the influence of liquid compressibility in the proposed method overstates the theoretical working volume by about $0.5 \%$. Is this value small or large? From the point of view of the motor user, a difference of $0.5 \%$ is negligibly small. Bigger differences are observed in the known methods, i.e., they are $0.8 \%$ and $3.1 \%$ in Toet's and Balawender's methods, respectively. A difference in the order of $1 \%$ and above, however, should not be underestimated, especially by designers and researchers of positive displacement machines. From their point of view, each difference in the theoretical working volume is important because it directly influences the assessment of mechanical and volumetric efficiency.

The theoretical working volume $q_{t}$ is constant in all ranges of speed $n$ and load $M$ of the motor. It has been shown above that with the change in the motor load (and thus the pressure drop in the motor) the working volume of the motor changes. Thus, the efficiencies defined according to Formulas (1) and (2) are subject to error. Therefore, the efficiencies should be calculated taking into account the actual working volume $q_{r}$ :

$$
\begin{gathered}
\eta_{m}=2 \pi \cdot \frac{M}{q_{r} \cdot \Delta p_{i}} \\
\eta_{v}=\frac{q_{r} \cdot n}{Q_{1}}
\end{gathered}
$$

where if $\Delta p_{i}=0$ then $q_{r}=q_{t}$.

For example, if the theoretical working volume calculated according to the simplified (omitting the influence of oil compressibility) Balawender's method is accepted for calculations of losses, the volumetric efficiency of the motor for $\Delta p_{i}<4 \mathrm{MPa}$ is larger than one $\left(\eta_{v}>1\right)$ (Figure 17). This makes no physical sense, of course.
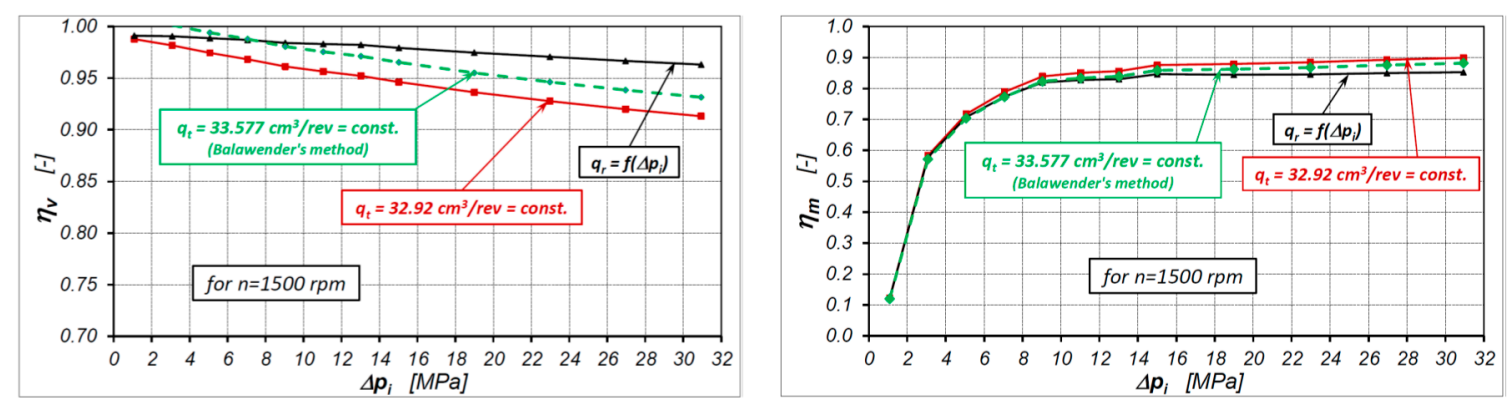

Figure 17. Comparison of volumetric efficiency $\eta_{v}$ (on the left) and mechanical efficiency $\eta_{m}$ (on the right) of the satellite motor at $n=1500 \mathrm{rpm}$ for different working volumes.

The theoretical working volume $q_{t}$ in all ranges of pressure drops $\Delta p_{\mathrm{i}}$ in the motor has commonly been accepted for assessment of losses in a hydraulic motor and its efficiencies, whereby it causes (Figure 17):

- an overestimation of volumetric losses and an underestimation of volumetric efficiency $\eta_{v}$;

- an underestimation of mechanical losses and an overestimation of mechanical efficiency $\eta_{m}$.

The results of the experimental research (Figure 16) confirm that the actual working volume $q_{r}$ is a nonlinear function of pressure drop $\Delta p_{i}$ in working chambers of the motor and can be described 
by a third order polynomial (expressed by Formula (29)). It should be clearly emphasized that the actual working volume $q_{r}$ is determined including the influence of oil compressibility and the pressure drop $\Delta p_{i c h}$ in the motor internal channels. Then $q_{r}=A=\mathrm{f}\left(\Delta p_{i}\right)$ and $q_{r}>q_{t}$ for $\Delta p_{i}>0$. Therefore, the values of $q_{r}$ according to Formula (29) should be taken into account to calculate the volumetric and mechanical losses in a hydraulic motor. In the tested satellite motor, this is:

$$
q_{r}=0.00002054 \cdot \Delta p_{i}{ }^{3}-0.00211551 \cdot \Delta p_{i}{ }^{2}+0.10404691 \cdot \Delta p_{i}+32.91602674
$$

From a practical point of view, it may seem a bit problematic to measure the pressure drop $\Delta p_{i c h}$ in internal channels of a hydraulic motor according to the method described in Section 3.4. For example, according to this method $\Delta p_{i c h}$ in an axial piston motor cannot be measured. Nevertheless, this measurement can be made using other methods, described in detail in [16].

Another issue requiring discussion is the value of geometric working volume $q_{g}$ of the motor resulting from the CAD drawing documentation. Thus, this geometric working volume $q_{g}$ is as much as $4.6 \%$ larger than the theoretical working volume $q_{t}$ calculated according to the proposed new method. Why such a big difference? Components of the working mechanism are made by electrical cutting with wire. Obviously, this cut is made with certain allowance for the finishing treatment (lapping). The manufacturer of the motor does not reveal the size of the allowance and the final geometrical dimensions after lapping. As a result, the geometrical working volume of a satellite motor is definitely smaller than that of the drawing documentation. In addition, there are teeth tip clearances in a satellite working mechanism, the effect of which is a certain volume included in the geometric working volume. It can be assumed that the impact of this volume on the process of pumping liquid through the working mechanism is small or negligible. However, this thesis would require proof.

Funding: This research was funded by the National Centre for Research and Development in Poland, grant number LIDER/35/102/L-2/10/NCBiR.

Conflicts of Interest: The author declares no conflict of interest.

\section{Appendix A}

Table A1. Equations $Q_{2}=A \cdot n+B$ of motor output flow rate at $\Delta p=$ const. (Toet's method).

\begin{tabular}{ccccc}
\hline No. & $\Delta p[\mathrm{MPa}]$ & $Q_{2}=A n+B$ & $A\left[\mathrm{~cm}^{3} / \mathrm{rev}\right]$ & $\mathbf{R}^{2}$ \\
\hline 1 & 2 & $Q_{2}=0.033120 \cdot n+0.245496$ & 33.120 & 0.999984 \\
\hline 2 & 4 & $Q_{2}=0.033369 \cdot n+0.379312$ & 33.369 & 0.999982 \\
\hline 3 & 6 & $Q_{2}=0.033590 \cdot n+0.441141$ & 33.590 & 0.999974 \\
\hline 4 & 8 & $Q_{2}=0.033762 \cdot n+0.462461$ & 33.762 & 0.999988 \\
\hline 5 & 10 & $Q_{2}=0.033973 \cdot n+0.476327$ & 33.973 & 0.999979 \\
\hline 6 & 12 & $Q_{2}=0.034124 \cdot n+0.498480$ & 34.124 & 0.999990 \\
\hline 7 & 14 & $Q_{2}=0.034256 \cdot n+0.518116$ & 34.256 & 0.999970 \\
\hline 8 & 16 & $Q_{2}=0.034411 \cdot n+0.566370$ & 34.411 & 0.999989 \\
\hline 9 & 20 & $Q_{2}=0.034689 \cdot n+0.649842$ & 34.689 & 0.999989 \\
\hline 10 & 24 & $Q_{2}=0.034968 \cdot n+0.735564$ & 34.968 & 0.999992 \\
\hline 11 & 28 & $Q_{2}=0.035170 \cdot n+0.800050$ & 35.170 & 0.999986 \\
\hline 12 & 32 & $Q_{2}=0.035349 \cdot n+0.852268$ & 35.349 & 0.999966 \\
\hline
\end{tabular}


Table A2. Equations $Q_{2}=A \cdot n+B$ of motor output flow rate at $\Delta p=$ const. (Balawender's method).

\begin{tabular}{ccccc}
\hline No. & $\Delta p[\mathbf{M P a}]$ & $Q_{2}=A \cdot n+B$ & $A\left[\mathbf{c m}^{3} / \mathbf{r e v}\right]$ & $\mathbf{R}^{2}$ \\
\hline 1 & 2 & $Q_{2}=0.033715 \cdot n+0.145474$ & 33.715 & 0.999960 \\
\hline 2 & 4 & $Q_{2}=0.033844 \cdot n+0.256944$ & 33.844 & 0.999785 \\
\hline 3 & 6 & $Q_{2}=0.034086 \cdot n+0.327206$ & 34.086 & 0.999926 \\
\hline 4 & 8 & $Q_{2}=0.034232 \cdot n+0.372550$ & 34.232 & 0.999909 \\
\hline 5 & 10 & $Q_{2}=0.034517 \cdot n+0.388903$ & 34.517 & 0.999904 \\
\hline 6 & 12 & $Q_{2}=0.034577 \cdot n+0.429866$ & 34.577 & 0.999537 \\
\hline 7 & 14 & $Q_{2}=0.034732 \cdot n+0.430350$ & 34.732 & 0.999907 \\
\hline 8 & 16 & $Q_{2}=0.034931 \cdot n+0.486725$ & 34.931 & 0.999677 \\
\hline 10 & 20 & $Q_{2}=0.035275 \cdot n+0.540842$ & 35.275 & 0.999824 \\
\hline 11 & 24 & $Q_{2}=0.035629 \cdot n+0.664698$ & 35.629 & 0.999920 \\
\hline 12 & 28 & $Q_{2}=0.035868 \cdot n+0.742994$ & 35.868 & 0.999823 \\
\hline
\end{tabular}

Table A3. Equations $Q_{2}=A \cdot n+B$ of motor output flow rate at $\Delta p_{\mathrm{i}}=$ const. (new method without the influence of the oil compressibility).

\begin{tabular}{ccccc}
\hline No. & $\Delta p[\mathbf{M P a}]$ & $Q_{2}=A \cdot n+B$ & $A\left[\mathbf{c m}^{3} / \mathbf{r e v}\right]$ & $\mathbf{R}^{2}$ \\
\hline 1 & 2 & $Q_{2}=0.033251 \cdot n+0.226334$ & 33.251 & 0.999992 \\
\hline 2 & 4 & $Q_{2}=0.033513 \cdot n+0.291487$ & 33.513 & 0.999989 \\
\hline 3 & 6 & $Q_{2}=0.033714 \cdot n+0.347383$ & 33.714 & 0.999992 \\
\hline 4 & 8 & $Q_{2}=0.033881 \cdot n+0.397161$ & 33.881 & 0.999995 \\
\hline 5 & 10 & $Q_{2}=0.034034 \cdot n+0.442995$ & 34.034 & 0.999996 \\
\hline 6 & 12 & $Q_{2}=0.034183 \cdot n+0.486303$ & 34.183 & 0.999995 \\
\hline 7 & 14 & $Q_{2}=0.034333 \cdot n+0.527925$ & 34.333 & 0.999994 \\
\hline 8 & 16 & $Q_{2}=0.034484 \cdot n+0.568284$ & 34.484 & 0.999995 \\
\hline 10 & 20 & $Q_{2}=0.034778 \cdot n+0.645530$ & 34.778 & 0.999996 \\
\hline 11 & 24 & $Q_{2}=0.035035 \cdot n+0.717189$ & 35.035 & 0.999992 \\
\hline 12 & 28 & $Q_{2}=0.035235 \cdot n+0.781090$ & 35.235 & 0.999979 \\
\hline
\end{tabular}

Table A4. Equations $Q_{(\mathrm{p} 1)}=A \cdot n+B$ of motor output flow rate at $\Delta p=$ const. (Toet's metod).

\begin{tabular}{ccccc}
\hline No. & $\boldsymbol{\Delta} \boldsymbol{p}[\mathrm{MPa}]$ & $Q_{(\mathrm{p} 1)}=A \cdot \boldsymbol{n}+\boldsymbol{B}$ & $\boldsymbol{A}\left[\mathbf{c m}^{\mathbf{3}} / \mathbf{r e v}\right]$ & $\mathbf{R}^{\mathbf{2}}$ \\
\hline 1 & 2 & $Q_{(\mathrm{p} 1)}=0.032787 \cdot n+0.245497$ & 32.788 & 0.999984 \\
\hline 2 & 4 & $Q_{(\mathrm{p} 1)}=0.032991 \cdot n+0.379312$ & 32.991 & 0.999983 \\
\hline 3 & 6 & $Q_{(\mathrm{p} 1)}=0.033168 \cdot n+0.441141$ & 33.168 & 0.999974 \\
\hline 4 & 8 & $Q_{(\mathrm{p} 1)}=0.033298 \cdot n+0.462462$ & 33.298 & 0.999988 \\
\hline 5 & 10 & $Q_{(\mathrm{p} 1)}=0.033468 \cdot n+0.476328$ & 33.468 & 0.999978 \\
\hline 6 & 12 & $Q_{(\mathrm{p} 1)}=0.033580 \cdot n+0.498481$ & 33.580 & 0.999991 \\
\hline
\end{tabular}


Table A4. Cont.

\begin{tabular}{ccccc}
\hline No. & $\Delta p[\mathrm{MPa}]$ & $Q_{(\mathrm{p} 1)}=A \cdot \boldsymbol{n}+\boldsymbol{B}$ & $\boldsymbol{A}\left[\mathrm{cm}^{\mathbf{3}} / \mathbf{r e v}\right]$ & $\mathbf{R}^{\mathbf{2}}$ \\
\hline 7 & 14 & $Q_{(\mathrm{p} 1)}=0.033674 \cdot n+0.518116$ & 33.674 & 0.999969 \\
\hline 8 & 16 & $Q_{(\mathrm{p} 1)}=0.033791 \cdot n+0.566370$ & 33.791 & 0.999989 \\
\hline 9 & 20 & $Q_{(\mathrm{p} 1)}=0.033996 \cdot n+0.649842$ & 33.996 & 0.999989 \\
\hline 10 & 24 & $Q_{(\mathrm{p} 1)}=0.034207 \cdot n+0.735564$ & 34.207 & 0.999992 \\
\hline 11 & 28 & $Q_{(\mathrm{p} 1)}=0.034340 \cdot n+0.800050$ & 34.340 & 0.999986 \\
\hline 12 & 32 & $Q_{(\mathrm{p} 1)}=0.034452 \cdot n+0.852269$ & 34.452 & 0.999965 \\
\hline
\end{tabular}

Table A5. Equations $Q_{(\mathrm{p} 1)}=A \cdot n+B$ of motor output flow rate at $\Delta p=$ const. (Balawender's metod).

\begin{tabular}{ccccc}
\hline No. & $\Delta p[\mathbf{M P a}]$ & $Q_{(\mathrm{p} 1)}=A \cdot n+B$ & $A\left[\mathbf{c m}^{3} / \mathbf{r e v}\right]$ & $\mathbf{R}^{2}$ \\
\hline 1 & 2 & $Q_{(\mathrm{p} 1)}=0.032566 \cdot n+0.137926$ & 32.566 & 0.999848 \\
\hline 2 & 4 & $Q_{(\mathrm{p} 1)}=0.032770 \cdot n+0.248459$ & 32.770 & 0.999924 \\
\hline 3 & 6 & $Q_{(\mathrm{p} 1)}=0.032906 \cdot n+0.316588$ & 32.906 & 0.999977 \\
\hline 4 & 8 & $Q_{(\mathrm{p} 1)}=0.032797 \cdot n+0.373599$ & 32.797 & 0.999991 \\
\hline 5 & 10 & $Q_{(\mathrm{p} 1)}=0.032923 \cdot n+0.404549$ & 32.923 & 0.999977 \\
\hline 6 & 12 & $Q_{(\mathrm{p} 1)}=0.032867 \cdot n+0.452474$ & 32.867 & 0.999993 \\
\hline 7 & $Q_{(\mathrm{p} 1)}=0.033010 \cdot n+0.443626$ & 33.010 & 0.999967 \\
\hline 8 & 14 & $Q_{(\mathrm{p} 1)}=0.033279 \cdot n+0.452977$ & 33.279 & 0.999982 \\
\hline 10 & $Q_{(\mathrm{p} 1)}=0.033603 \cdot n+0.509748$ & 33.603 & 0.999537 \\
\hline 11 & 20 & $Q_{(\mathrm{p} 1)}=0.033501 \cdot n+0.682885$ & 33.501 & 0.999856 \\
\hline 12 & 24 & $Q_{(\mathrm{p} 1)}=0.033663 \cdot n+0.722821$ & 33.663 & 0.999790 \\
\hline
\end{tabular}

Table A6. Equations $Q_{(p \mathrm{H})}=A \cdot n+B$ of motor output flow rate at $\Delta p_{\mathrm{i}}=$ const. (new method).

\begin{tabular}{ccccc}
\hline No. & $\Delta p_{\mathbf{i}}[\mathbf{M P a}]$ & $Q_{(p \mathrm{H})}=A \cdot \boldsymbol{n}+\boldsymbol{B}$ & $\boldsymbol{A}\left[\mathbf{c m}^{3} / \mathbf{r e v}\right]$ & $\mathbf{R}^{\mathbf{2}}$ \\
\hline 1 & 2 & $Q_{(p \mathrm{H})}=0.033095 \cdot n+0.223310$ & 33.095 & 0.999982 \\
\hline 2 & 4 & $Q_{(p \mathrm{H})}=0.033308 \cdot n+0.346180$ & 33.308 & 0.999991 \\
\hline 3 & 6 & $Q_{(p \mathrm{H})}=0.033487 \cdot n+0.404302$ & 33.487 & 0.999993 \\
\hline 4 & 8 & $Q_{(p \mathrm{H})}=0.033638 \cdot n+0.431194$ & 33.638 & 0.999992 \\
\hline 5 & 10 & $Q_{(p \mathrm{H})}=0.033769 \cdot n+0.448067$ & 33.769 & 0.999990 \\
\hline 6 & 12 & $Q_{(p \mathrm{H})}=0.033886 \cdot n+0.466857$ & 33.886 & 0.999988 \\
\hline 7 & 14 & $Q_{(p \mathrm{H})}=0.033997 \cdot n+0.492843$ & 33.997 & 0.999988 \\
\hline 8 & 16 & $Q_{(p \mathrm{H})}=0.034105 \cdot n+0.526875$ & 34.105 & 0.999989 \\
\hline 10 & 20 & $Q_{(p \mathrm{H})}=0.034315 \cdot n+0.610846$ & 34.315 & 0.999990 \\
\hline 11 & 24 & $Q_{(p \mathrm{H})}=0.034497 \cdot n+0.696203$ & 34.497 & 0.999988 \\
\hline 12 & 28 & $Q_{(p \mathrm{H})}=0.034626 \cdot n+0.764548$ & 34.626 & 0.999979 \\
\hline
\end{tabular}




\section{References}

1. Wilson, W.E. Positive Displacement Pumps and Fluid Motors; Publication Corporation: New York, NY, USA, 1950.

2. Schlosser, W.M.J. Meten aan Verdringerpompen. Ph.D. Thesis, Technical Hogeschool Delft, Delft, The Netherlands, 1957.

3. Schlosser, W.M.J.; Hilbrands, J.W. Das Theoretische Hubvolumen von Verdrangerpumpen; No. 4. Olhydraul. und Pneum. 1963, 7, 133-138.

4. Schlosser, W.M.J.; Hilbrands, J.W. Das Volumetrische Wirkungsgrad von Verdrongerpumpen; No. 12. Olhydraul. und Pneum. 1963, 7, 469-476.

5. Toet, G. Die Bestimmung des Theoretischen Hubvolumens von hydrostatischen Verdrangerpumen und Motoren aus Volumetrischen Messungen; No 14. Olhydraul. und Pnaum. 1970, 14, 185-190.

6. Toet, G.; Johnson, J.; Montague, J.; Torres, K.; Garcia-Bravo, J. The determination of the theoretical stroke volume of hydrostatic positive displacement pumps and motors from volumetric measurements. Energies 2019, 12, 415. [CrossRef]

7. Balawender, A. Opracowanie Metodyki Wyznaczania Teoretycznej Objętości Roboczej Pomp i Silników Hydraulicznych Wyporowych (The Development of the Methodology for the Determination of the Theoretical Working Volume of Positive Displacement Pumps and Hydraulic Motors). Ph.D. Thesis, Gdansk University of Technology, Gdansk, Poland, 1974.

8. Balawender, A. Analiza energetyczna i metodyka badań silników hydraulicznych wolnoobrotowych (Energy analysis and methodics of testing of low-speed hydraulic motors). In Scientific Book of the Gdansk University of Technology; Mechanika No. 54; Gdansk University of Technology Publishing House: Gdansk, Poland, 1988.

9. Garcia-Bravo, J.; Nicholson, J. What is the real size of that pump? Fluid Power J. 2018. Available online: https:/fluidpowerjournal.com/real-size-pump/ (accessed on 1 September 2020).

10. Manring, N.; Williamson, C. The theoretical Volumetric Displacement of a check-valve type, digital displacement pump. J. Dyn. Syst. Meas. Control 2019, 141, 12-14.

11. Myszkowski, A. Energy analysis of an ideal suction-pressure unit. Arch. Mech. Technol. Mater. 2015, 35, 51-60.

12. Post, W. Models for steady-state performance of hydraulic pumps: Determination of displacement. In Proceedings of the 9th Bath International Fluid Power Workshop, University of Bath, Bath, UK, 9-11 September 1996; Volume 9.

13. International Organisation for Standardization. ISO 8426:2008: Hydraulic Fluid Power. Positive Displacement Pumps and Motors. Determination of Derived Capacity; ISO Copyright Office: Geneva, Switzerland, 2008.

14. Kim, T.; Kalbfleisch, P.; Ivantysynova, M. The effect of cross porting on derived displacement volume. Int. J. Fluid Power 2014, 15. [CrossRef]

15. Stryczek, S. Napęd Hydrostatyczny; WNT: Warszawa, Poland, 2005.

16. Sliwinski, P. Satellite Displacement Machines. Basic of Design and Analysis of Power Loss; Gdansk University of Technology Publishers: Gdansk, Poland, 2016.

17. Osiecki, L. Commutation Units of Hydraulics Axial Piston Machines; Gdansk University of Technology Publishers: Gdansk, Poland, 2006.

18. Zaluski, P. Influence of the Position of the Swash Plate Rotation Axis on the Volumetric Efficiency of Axial Piston Pumps. Ph.D. Thesis, Gdansk University of Technology, Gdansk, Poland, 2017.

19. Sliwinski, P.; Patrosz, P. Satellite Operating Mechanism of the Hydraulic Displacement Machine. Patent PL218888, 27 February 2015.

20. Sliwinski, P. The methodology of design of axial clearances compensation unit in hydraulic satellite displacement machine and their experimental verification. Arch. Civ. Mech. Eng. 2019, 19. [CrossRef]

21. Sliwinski, P. The influence of water and mineral oil on mechanical losses in a hydraulic motor for offshore and marine application. Pol. Marit. Res. 2020, 27. [CrossRef]

Publisher's Note: MDPI stays neutral with regard to jurisdictional claims in published maps and institutional affiliations. 